\title{
Social work practice in health: An introduction to context, theories and skills
}

\author{
Melissa Petrakis (Ed.), 2018 \\ Allen \& Unwin, Australia \\ ISBN 978-1-76029-451-9, pp. 288, NZD56.99
}

I recently started a secondment position at the University of Auckland, and am to be involved in supporting lecturers and students bringing the practice world of social work in health closer to the academic world.

When approached to review the book, I was initially hesitant, but when I saw the title, I was immediately attracted. Finally - a whole book about social work in health! Social workers in practice it find it challenging to make time to stay up to date with the latest literature. To come across an edited book, with information covering different areas of social work in health, and written from a perspective which can be applied within the health context of New Zealand, is exciting.

The first chapter provided a good foundation for the rest of the book. It gives an overview of what the role of social workers in health might entail, the challenges to social workers, and the connection to social determinants of health. The second chapter encourages social workers towards evidence-informed practice and to engage in practice research. Social workers not engaging in research as much as other allied health professions seems to be common and, due to practice demands, social workers might need more support from management levels to contribute in this area of social work.

The title gives the impression that context, theories and skills will be discussed in even amounts of detail, but I found that the context and role of social work weighed heavier. Most chapters make reference to theories relevant to the working environment and one would need to have foundational knowledge about social work theories to integrate and make the connection between practice and theory within the variety of contexts of social work in health. However, credit should be given to the chapter on forensic social work (Chapter 10) which captured aspects of theory in more detail.

Practice skills which might be relevant in the health context are also discussed, but a social worker would still need to be practising social work in the field to apply and develop basic social work skills to fit within the health environment.

I did enjoy the unexpected gems that surprised in some chapters, for example the short but dynamic explanation of crises support/psychological first aid (Chapter 4), psycho-education (Chapter 7), the importance of supervision (Chapter 8), motivational interviewing (Chapter 9), and additional aspects to consider when performing assessments for older people (Chapter 13). As a social worker in the field of cancer, Chapter 12 impressed, capturing the foundational aspects of a huge context effectively.

As a social worker who appreciates a strong, supportive counselling approach in my social work practice, I observed the careful and limited presence of the role and value of the therapeutic role of social work in health in this book. In practice, the application of these skills may be limited due to the pressure on social workers to focus on 
discharge planning and supporting patients in practical matters. It seems to me that this contributes to a perspective of a narrow scope of practice in the context of (especially physical) health. However, it is still an essential skill which social workers should be able to integrate with confidence within their social work practice.

In general, I appreciated the information written in language that is easy and quick to read, with the information quite succinct. The chapters are well organised, creating the feel of flowing naturally from one context to the next. The first two chapters provide a foundation, then the different contexts are addressed. It starts with children, then women, mental health and aged care. It includes complicated areas such as traumabased social work, oncology and end-of-life care, disability and refugee health.

Cultural components are also addressed, and appreciation is expressed for considering a Māori-informed approach to health social work. However, in reading this chapter, I found it hard to connect with the information, as it seems to me that there are practice challenges in the application of the approach, e.g., the role of whānau advocates that are impacted by changes within the district health boards, shorter hospital stays, and a bi-cultural approach may not be evident in the health context of Aotearoa New Zealand. Social workers might have a stronger role to play in ensuring that bi-cultural practice approaches are applied within the context of health in Aotearoa New Zealand.

It was interesting to find a chapter on forensic social work in this book, but I struggled to make the connection within the context of health. It seemed that the link between corrections and the health context was missing, e.g., the role of social work when supporting a person linked with the correctional system who needs to go for medical treatment or to access appointments.

This book is relevant to the context of Aotearoa New Zealand taking into consideration that the health systems of Australia, UK and Aotearoa New Zealand are quite similar. For Aotearoa New Zealand, all aspects of this book might not be relevant (for example, relating to the area of disability, the National Disability Insurance Scheme). The local reader will have to familiarise themselves with the context of Aotearoa New Zealand. This also applies to matters relating to policy, legislation and demographics. I do think that this book will especially be valuable to students and social workers who are interested in pursuing their career working in the area of health. It provides a foundation for social work within the context of health and could contribute to the professional confidence of the social worker working in this field. This book will definitely form part of the reading list of every session I am involved with in the lecturing of students. Congratulations. 